\title{
ELS OFICIS A LA BARCELONA MEDIEVAL: ELS CAPELLERS VERS 1300.
}

\author{
Carme BATLLE \\ Universidad de Barcelona
}

Com a continuació dels estudis dedicats al món del treball a la Barcelona baixmedieval, alguns ja publicats,(1) ara presentem la casa i l'obrador d'un capeller establert a la Vilanova de la Mar juntament amb algunes notícies sobre altres del mateix ofici. Sembla una bona època pels artesans de l'abillament, entre ells els capellers, que aprofiten l'extraordinària difusió de toda mena de barrets, ja que la moda afavoria la utilització d'aquest complement i per altra part resultava imprescindible per protegir-se de diferents fenòmens meteorològics, como el sol i la pluja. Tothom n'havia de fer servir tant a livern como a l'estiu des dels monarques a la gent del poble, com ho manifesta un conegut episodi del "Llibre dels Fets" de Jaume I el Conqueridor durant el setge de la ciutat de València. Aquí el rei fou lleument ferit al front d'un tret de ballesta per haver prescindit de l'elm o capell de ferro i haver-lo sustituit per un de palla amb motiu de la intensa calor, tot i que encara portava dues peces que protegien el cap del fregadís del ferro.(2)

La diferenciació social es manifestava externament en el vestir i exigia diversitat i calitat dels barrets que eren molt variats segons els materials emprats i les formes, però el més usats resulten ser els de sol. A més, el barret no solament diferenciava els estaments sinó que també caracterizava el sexe i la religió, per exemple en el cas dels jueus. Quant a les dones, la soltera podia portar garlanda de flors - corona virginal o gandaia - mentre que la casada cobria el cap amb un vel o un toca amb mentonera. És curiós que en l'inventari de l'obrador de Pere Ruvira que comentarem, no s'especi- 
fica mai quins barrests són d'home i quins de dona, potser perquè elles en posseïen molt pocs. En realitat, només trobem poques barcelonines del segle XIII que n'esmentin entre els seus béns, i de fet són tres, que tenian un capell de color morat, un de seda i amb plomes de paó, respectivament.(3)

Alguns personatges exigien capells d'importació, de Sicilia, Alemanya o Castella, com en tenia a la botiga l'esmentat Ruvira, però altres en portaven d'estil sarraí, com jurista Guillem Eimeric, de la mateixa època d'en Ruvira, que tenia un barret moro de presset, anomenat sarboix, i un de feltre. D'un altre tipus era el capell d'almogàver, de fil negre, que consta en l'inventari de Pasqual d'OIm.

Els capellers formaven part del nombrós grup d'artesans dedicats a la producció de les diverses peces de l'abillament que es concentraven al voltant de l'església de Santa Maria del Mar, nucli comercial per excel.lència de la ciutat durant segles. Era la Vilanova de la Mar creada en gran part pels mateixos mestres dels oficis en un punt ben comunicat $i$ adient pel transport de mercaderies per mar i per terra, i també proper als alfòndecs reials. El carrer preferit per ser el més concorregut era el de la Mar, després anomenat de l'Argentaria, però els noms dels carrers veins demostren l'extensió dels obradors per tot el barri. Entre aquests noms d'oficis dels carrers propers a l'església perdura els dels sombrerers tocant a la paret del mateix edifici.

En el carrer de la Mar hi tenien casa i obrador alguns mestres, com el ric pelleter Pere de Malla,(4) alguns argenters - per això canvià el nom del carrer -, costureres i sastres, per exemple Pere Dorca, que procedent de Sant Genís dels Agudells s'establí aquí vora l'església el 3 d'agost de 1266 en una casa, tota sencera per ell, propietat d'Agnès Crony i alou de la canonja. Més endavant vivgia i treballava aquí a la vora, al mateix carrer de la Mar, el capeller Pere Ruvira, que és el protagonista del present estudi. No tots els capellers es concentraven al carrer del seu nom o a la rodalia, sinó que en trobem més amunt, en el burg, davant la capella-hospital d'En Marcús; és Pere Capeller, que hi vivia mitjan segle XIII.(5) En un moment de formació dels cognoms encara es pot afirmar la identitat de l'ofici i del cognom, com ho confirma el cas de Bertomeu Capeller, que devia o millor dit, havia de fer per a Pere Ruvira sis dotzenes de barrets negres de sol, com consta en l'inventari de la casa-obrador de Ruvira. També existia un Nicolau Capeller, de la Seu d'Urgell, mitjan segle XIV.

Tot i disposar de l'obrador, que no solia ser gaire espaiós, els artesans invadien molt la via pública per les petites dimensions del seu lloc de treball o si tenien diversos ajudants: a més, exposaven els productes elaborats en taules de fusta plegadisses i en algunes d'obra que romanien un cop tancat el taller, $i$ en perxes de colors vius penjades a les parets properes a la seva porta. Tot això entorpia el pas de vianants i cavallers en uns carrers més 
aviats estrets i hagué de ser objecte de reglamentació per part de les autoritats municipals. En una ordinació dels consellers promulgada vers 1318 , després dels oficis del metall establerts en el carrer de la Mar que penjaven els seus productesen perxes fixades a les parets exteriors per atreure els clients, consten les costureres:..." ne encara neguna custurera no tenga ne gos tenir ne fer exir les pertxes en què les dites coses tendrà fora la paret sinó II palms e mig de destrer."(6) Per tant l'exhibició dels objectes o dels vestits produits a l'interior de l'obrador era un costum normal de tots els artesans, que els penjaven en perxes ben virolades per cridas l'atenció dels vianants; naturalment també ho feien els capellers, com l'esmentat Pere Ruvira. Uns anys més tard, el 1365, els consellers insistien en el mateix problema i prohibien als paraires $i$ botiguers penjar robes en perxes o bastons sortint molt d'obradors i botigues, i per no molestar als vianants, només ho podien penjar a les parets. (7)

Els capellers formaven part d'una gran cofraria juntament amb altres oficis relacionats més o menys amb la merceria ( mercers, guanters, pinters, cordoners, etc. ) sota l'advocació de sant Julià, però cadascun tenia un veedor propi o delegat encarregat d'unes qüestions concretes.(8) De tota manera no és fins l'any 1392 que els passamaners constituiren el nucli principal dels anomenats julians sota la protecció de l'esmentat sant en el convent de Sant Agustí del barri de Ribera. Més tard s'hi afegiren corretgers, bossers i altres; el 1455 ho feren els capellers i naipers, i després els cinters, botoners, etc.(9) Per tant els capellers acudien a la casa gremial dels julians situada a la placeta dels Fustarners unida a la plaça del Blat o de l'Àngel.(10) Aquesta afinitat entre barreters i mercers, que també podien vendre capells, la trobem ben manifesta a la Seu d'Urgell, on hi havia al mateix temps un Nicolau Capeller $i$ el mercer Pere Roll, ciutadà urgellès, que tenia barrets a la venda en el seu obrador, entre coses ben diverses.(11)

A la fi de l'època medieval, quan el nom de capellers ha estat substituit pel de barreters, es promulga la primer ordinació municipal referent a aquest ofici (1503), data en què es tracta el problema provocat per alguns mestres que fan treballar artesans dels poblets veins de la ciutat, perquè la mà d'obra és menys cara que a Barcelona.(12) Unes altres ordinacions, de mitjan segle XVI, foren comentades per Antoni de Capmany, l'únic historiador que ha dedicat una especial atenció als capellers en un apartat del seu estudi sobre el gremis barcelonins.(13) Si bé les tres disposicions aprovades pels honorables consellers de la ciutat en un consell ordinari per corregir els fraus i abusos d'alguns consellers no passen de l'any 1545,(14) en el seu pròleg es fa al.lusió al prestigi d'aquests artesans en temps passats, quan exportaven els seus productes a França, i a Itàlia amb gran benefici per a la hisenda municipal. Els abusos s'havien detectar "en lo ennegrir e tenyir dels sombreros blanchs", frau que determinava una minva en l'honor i en la reputació de 
l'ofici, i també en l'exportació del génere. Per tant, la producció, i el tint en concret, havia de ser controlada pel mostassà i els veedors de l'ofici, i si no reunia les condiciones necessàries, s'havia de destruir i el culpable hauria de pagar una multa de 50 sous. La segona disposició regulava el material emprat en la confecció dels barrets: s'havien de fer amb llana d'anyell i no de llana de Sardenya ni de "xepeus e feltres peluts", sota la pena de la mateixa multa. La tercera ordinació prohibia vendre com a nous barrets vells renovats, sota pena de la multa corresponent. A més, s'estipulava que les sumes recollides procedents de les infraccions s'havien de dividir en tres parts, una pel mostassà, l'altra per la casa de la confraria i la darrera per les obres dels murs i valls de la ciutat.

Aquestes són notícies sobre l'ofici durant l'Edat Mitajan i l'inici de la moderna, que enmarquen l'estudi de l'activitat d'un capeller concret, Pere Ruvira, vers 1300.

\section{EL CAPELLER PERE DE RUVIRA.}

Les escasses notícies recollides sobre l'ofici dels capellers, i encara concentrades en una època molt tardana, manifesten la manca de fonts en els segles precedents, quan en realitat es tracta d'una activitat constant e la nostra ciutat perquè de barrets se n'han portat sempre. L'escassesa dóna mes relleu a la persona de Pere Ruvira, actiu pels volts de 1300 , i confereix més importància a l'inventari de les existències dela seva casa-obrador datat de l'11 de febrer de l'any 1309.(15) En realitat no sabem res d'aquest home, ni la seva procedència, ni qui eren els seus parents, tot i que a la mateixa època vivien en Barcelona diverses famílies amb aquest cognom, que semblen disfrutat d'un estatus social més alt que el capeller. Desconeixem on tenia l'obrador abans de comprar la casa al carrer de la Mar, però és evident que ja exercia l'ofici en un altre lloc pel gran stock de capells inventariats a la seva botiga poc abans de la seva mort; es veu clar que no era una instal.lació recent, mentre que l'adquisició de la casa sí que ho era, pel gran nombre de barrets, pels col.laboradors del negoci i per l'edat madura del mestre, casat amb una vídua que ja tenia un fill negociant.

Tampoc sabem exactament quines foren les causes precises que influiren en Ruvira per fer un inventari dels seus béns, però devia ser la seva malaltia i la proximitat de la mort, ja que poc després els marmessors disposaren la venda de la casa com a executors testamentaris. En aquestes circumstàncies era normal fer testament; ja no ho era tant establir l'inventari de tot, que havia de fer per força la vídua o el tutor de fills menors. Aquí és el mateix capeller, malalt, l'interessat en fer-no, juntament amb la muller, per aclarir en vida i regular davant la llei algunes qüestions d'interessos, evitar la dispersió de tot i el frau, idees que manifesten una situació familiar conflicti- 
va, puix que no hi havia fills i ell disposava de tots els béns en favor de Déu i dels pobres. El notari sol.licitat fou Bernat de Vila-rúbia i els marmessors Berenguer Aguiló, també capeller, Pere Montví, sabater, i el prevere Bertomeu de Colomar, que actuaren com a tals amb gran celeritat. Poc després de la data de l'inventari (11 de febrer de 1309), van vendre la casa de Ruvira, ja designat com a difunt en el document de venda, a la seva vídua Benvenguda, ara vídua per segona vegada, i a Guillem de Palau, fill del primer matrimoni d'ella, pel preu de 80 lliures de moneda barcelonesa de tern, amb la intervenció amb un anomentat també Guillem de Palau, dels corredors Jaume de Bonany i Simó de Canyadell, que havien tingut just el temps de fer cridar la venda públicament per la ciutat durant trenta dies. D'aquesta quantitat es pagà el sou dels corredors, el lluisme i altres despeses, deixant la resta pels pobres.(16)

El fet de disposar de l'inventari i de documents de la marmessoria ens permet conéixer millor la vida del capeller, integrat segurament en una col.lectivitat més àmplia d'artesans que operaven al mateix barri. Sabem on era situat el seu obrador, que més endavant descriurem en detall, però podem precisar que la seva ubicació respon exactament a les tendències comercials del moment $i$ al sistema de construcció de l'època, en què les cases sofrien divisions per mitjà de parets $i$ envans, i ampliacions amb taules o mostradors exteriors, que ocasionavan nombrosos conflictes. En efecte, també ho feú el capeller, que aconseguí permís per portar a terme un cert engrandiment de l'obrador tot invadint part del carrer. Fou el 17 de maig de l'any 1308 quan el batlle de Barcelona Arnau Cuc li autoritzà i Ruvira va poder posar taules de fusta clavades a la paret de fora de l'obrador.(17) La citada disposició dels marmessors fa referència de la venda a la vídua i al seu fill de les taules exteriors, portes i envans.

Ruvira estava ben integrat pel seu ofici dins de la producció artesana de l'abillament i de la vida comercial de Barcelona. Posseïdor d'un cert capital i situat el seu obrador-vivienda en el millor punt de confluència de mercaders i compradors, participà de l'evolució mercantil i comercial dela ciutat, com ho demostren els seus contactes i transaccions amb diverses persones. A l'inventari consten documents conservats a casa que contenen informació sobre els mitjans emprats pel capeller per tirar endavant el negoci. La majoria d'instruments fan referència a l'adquisició de la finca i en total són quatre: la compra de l'hospici; el rebut de la propietària, Suau, del preu pagat pel capeller 65 lliures; el document de procuració signat per Suau en favor del seu marit, Bernat Sunyer, que s'encarregà de transferir la propietat a Ruvira; la presa de possessió de la finca per aquest darrer.

Els altres documents inventariats que permeten comprovar la relació del capeller amb altres menestrals, comerciants o ciutadans barcelonins, es refereixen a penyores, préstecs, comandes i a una taula de canvi. Com que 
disposava d'un modest capital, sembla que feia algun préstec a la menuda, ja que tenia a casa tres objectes com a penyora: una tovallola de seda, obra sarraïna, de Bernat Bellvís per 6 sous i 2 diners; un morter de coure amb la seva mà de Bonanat Estrany per 3 sous, i una taça d'argent del seu fillastre Guillem Palau per 30 sous. Actuava com a prestador en un cercle reduit, segurament de veins: Pere de Terrassa li devia 50 sous sense cap document acreditatiu, detall que demostra confiança; Bernat Busquet 8 sous i 4 diners; Bernat de Resguardona 4 sous que li havia prestat per fer taules o mostradors al seu propi obrador, i Bartomeu Capeller estava obligat a fer-li sis dotzenes de capells negres de sol. També era seu el capital d'una comanda de 10 lliures concedida al seu fillastre en poder del notari barceloní Bernat de Solans el 20 de gener de 1309; potser era la mateixa suma que Guillema, vídua del sabater Ramon de Granella, havia dispositat en poder de Ruvira. A més, tenia relació amb el canviador Bernat Oliveres, en la taula del qual tenia dipositades 8 lliures en moneda barcelonesa de tern. El banquer pertanyia a una coneguda familia de la ciutat enllaçada amb els Llull, de la mateixa professió.(18)

Com es pot veure per aquestes escasses transaccions, Ruvira participà en el negoci de manera limitada, però féu moure el seu capital, en gran part esmerçat en gènere, segons els sistemes normals a l'època, és a dir préstecs i comandes. Més al seu nivell d'artesà establí relació amb altres homes del mateix ofici, que treballaren per ell. Un es Bertomeu Capeller, que estava obligat a fer-li sis dotzenes de barrets de sol, i el cognom del qual procedeix de l'ofici exercit. També Berenguer Aguiló, veí de la carrera del Mar, devia ser capeller perquè tenia en co-propietat amb Ruvira dotze capells de sol negres. A més del negoci en comú, sembla que una bona amistat unia els dos homes: Ruvira fou fidejussor d'Aguiló en relació amb el traginer Sagalars i els 9 documents sobre l'assumpte ( exportació de capells ?) estaven en poder del sabater Montví, testimoni de l'inventari comentat, mentre que Aguiló era marmessor del testament del nostre capeller. Un col.laborador de Ruvira fou Enric Capeller o Enric d'Alemanya, nos que defineixen el seu origen i el seu ofici - Enric no és un nom utilizat pels barcelonins - ; consta com a testimoni de l'inventari, en el qual s'especifica queel mestre li devia diners, encara que ja li havia pagat 48 sous. Tot manifesta la col.laboració de l'alemany, segurament autor dels capels designats com alemanys de l'obrador de Ruvira. En darrer lloc hem d'esmentar el perpunter Guillem Barceló, al qual el mestre pagà 4 sous i 2 diners; fou testimoni de l'inventari.

$\mathrm{Cal}$ remarcar l'existència de quatre homes del mateix ofici, però havien de ser més nombrosos per servir una població potser d'uns 40.000 habitants. En canvi, era normal quea la petita ciutat de la Seu d'Urgell, d'uns mil habitants, només n'hi hagués un a mitjan segle XIII: Bernat Pallarès, capeller, hi vivia amb la seva esposa Sança; i un altre, Nicolau Capeller, i el mercer Roll al cap d'un segle.(19) 
En Ruvira, ben integrat en el món artesanal, devia viure exclusivament del seu negoci, que hem analitzat, ja que ni en l'inventari ni en la marmessoria no hi ha cap indici de béns o rendes agrícoles, és a dir, algun ingrés complementari de la seva economia. Sembla, doncs, que tots els seus béns i pertinences, així com totes les despeses, procedien dels beneficis generats pel seu treball, exceptat el dot aportat per la seva dona al matrimoni, detall desconegut per a nosaltres. Potser el dot de Benvenguda fou esmerçat en l'adquisició de la casa-obrador del capeller, perquè ella posseïa una propietat, és a dir, un hort o pati, al mateix carrer de la Mar. Sigui com sigui el fet és que Ruvira adquirí la finca a Suau, esposa de Berenguer Sunyer, que va a actuar com a procurador d'ella, el 1308. Devia ser un edifici ( hospicium ) bastant gran si tenim en compte l'elevada suma pagada, 65 lliures,(20) pel capeller, que encara guanyà espai amb les taules exteriors. La venedora de la casa tampoc era propietària directa sinó una emfiteuta, ja que la finca era alou de la canonja de Barcelona, exactament de la prepositura del mes d'abril. Com que la casa formava part d'un conjunt d'edificis, on hi vivia la mateixa Suau i altra gent mitjançant el pagament d'un cens, podem conéixer alguns veïns.

L'esmentada Suau era filla del difunt Guillem de Roudors i de Guillema, potser pertanyents a la menestralia, com sembla indicar el cognom que es pot relacionar amb el roldor, planta amb unes fulles aptes a adobar pells. El matrimoni només va tenir filles, la més gran de les quals, Suau, potser fou nomenada pubilla i quedà única propietària de la finca, encara que la mare i les germans hi tenien certs drets; les germanes eren la difunta Beatriu, Subirana, vídua de Ramon Arnau, i Joaneta, vídua d'Arnau Oliveres. Sembla que en un moment difícil per a la família es féu amb una diferència de mesos la venda de la casa al capeller a l'inici de 1308 i el 15 d'octubre la venda dels drets de Suau per 345 lliures, 6 sous, i 8 diners ( a raó de 10 sous per morabatí ) als germans Guillem i Pere d'Oliveres, ciutadans barcelonins i fills del difunt Ramon d'Oliveres, originari de Banyoles, quedant ells dos com a emfiteutes directes de la canonja. Per tant, en l'inventari el capeller manifesta tenir la casa per Guillem d'Oliveres, ciutadà de Barcelona. En el document de venda Suau descriu la seva propietat(21): el domini, censos i altres drets sobre les taules del carrer amb envà que hi té el capeller a cens de 10 morabatins alfonsins i un diner de Barcelona de tern pagadors per Santa Maria de febrer; sobre l'obrador "a sostre inferius cum anvario" $i$ taules exteriors de Pere de Fluvià, bainer, a cens de 7 morabatins i un diner de tern, i sobre un altre obrador definit igualment de l'argenter Bartomeu per 6 morabatins $i$ un diner; un altre de Bernat de Resguardosa per mateix cens, $i$ un espais de terra o hort de Benvenguda, la muller del capeller, a cens de 2 morabatins i un diner, amb dos portals i pertinences, tot alou de la canonja. 
La casa de Ruvira i els obradors dels menestrals esmentats eren contigus i a l'est limitaven amb la resta de la finca de Suau, al sud amb l'honor de Resguardosa, que el tenia pels hereus del difunt Guillem David, a l'oest amb el carrer de la Mar i al nord amb l'honor de Ramon Ricard amb parets comunes. La casa amb pati de Resguardosa i el pati de Benvenguda, la muller de Ruvira, eren contigus i limitaven a l'est amb l'honor que l'esposa de Bernat Enfermí argenter, tenia sota l'alou de la mateixa prepositura de la catedral, al sud amb la via pública i a l'oest amb l'honor del difunt Guillem Baster.(22) En conjunt, ens trobem amb un teixit urbà molt dens, en el qual el propietari aloer és la canonja, el primer emfiteuta un ciutadà honrat, com Ricart, o un draper com Baster, mentre que els veïns són menestrals. El mateix es pot comprovar a tot el barri, per exemple a la propietat dels Grony, el record dels quals encara perdura en el nom del carrer Gruní.

\section{La casa del capeller}

Podem fer una relació dels béns de Pere Ruvira, tant dels de la casa com els de l'obrador, però no es possible comparar-los amb els d'altres menestrals de la mateix categoria i del ram de l'abillament, per manca d'inventaris similars i d'una època tan primerenca. No sempre és fàcil destriar quins estris pertanyen a l'obrador i quins propiament a la vivenda perquè a l'inventari es van esmentat coses sense una classificació lògica. És queen aquesta època la concepció i distribució de l'espai és molt diferent de l'actual;(23) de fet podem trobar barrejats objectes ben diversos. En l'inventari no queda gens clar com era la propietat perquè el devia fer el mateix capeller començant pels diners i coses de valor de l'obrador en presència del notari. En famílies benestants el més normal era tenir l'obrador a peu plà del carrer i la vivenda al primer pis, però aquesta distribució no es pot entreveure ni en l'inventari ni en la informació complemèntaria.

Cal remarcar l'absència de molts atuells casolans, com cremalls, olles o escudelles, que no consten perquè devien ser propietat de la muller d'En Ruvira, com també els vestits d'ella, que essent vídua ho devia aportar en contraureel segon matrimoni. Encara que alguns mobles i objectes, per exemple els estrits de pastar, es troben entreels capells, hem intentat reunirlos d'una manera més lògica per descriure el conjunt més ordenadament, mentre que la realitat és la de l'inventari. Comencem per la part de la vivenda, que potser era una sola peça com sala, alcova i cuina, al costat de l'obrador. Corresponden al primer àmbit un moble, que és un escudeller sense escudelles, un llumener de ferro, una taula de fusta per menjar que consta més endavant entre la roba, dos bancs de fusta, una banqueta, un retaule de fusta $i$ una caixeta de fusta inventariats entre els barrets i juntament amb els 
estris de fer el pa: una pastera de fusta, una post de fusta segurament per portar el pa a coure al forn, un sedàs per la farina, un banc i una caixeta. Propis de la bateria de cuina són una paella d'aram trencada amb la seva giradora de ferro, una tapadora també de ferro, un coltell de ferro i un morter amb la seva mà, tot de coure, que no podia mancar a cap cuina, i una sitra de llautó. Consten dos llits complets: un de fusta amb màrgefa, matalàs i un llençol de fil, després hi ha un coixí obrat de seda, un cobertor de bord ( tela medieval que ara no es pot definir ), una vànova blanca $i$ una caixa de fusta que sempre era a la vora a als peus del llit; un llit de posts amb màrfega i un capçal de plomes, després hi ha una flassada llistada, un cobertor lívid, osia el color de la llana crua, gris sogroguenc, trencat i també una caixa de fusta; més endavant consta un altre capçal de plomes. Com que les armes no mancaven a cap casa, el capeller tenia una espasa i un parell de guants, i després una llança.

Dins d'una de les caixes hi havia la roba del capeller: una sobretúnica de roba grisosa amb pell de conill negra i dues dotzenes de botons d'argent, una gramalla de roba potser de ras, o sia de seda, amb pell de conill blanca, quatre "magrins" d'argent i la caputxa de la mateixa roba amb sendal vermell, un parell de calces blanques i una camisa. Segueix la relació de roba i objectes que, suposem, ja no es trobaven dintre la caixa: un llençol dolent, un altre i un tovalló de fil, una aluda o bossa de cuir blanc buida, un cabdell de fil d'estopa, un computador de fusta ( un àbac? ) i un "vern" de ferro, que no podem identificar, un capell de sol de lli pentinat, un cabàs amb un capell de lli, unes tovalles i un llençol trencat, un altre d'estopa, una estora, una cistella i un gavadal de fusta, més avall un bací de llautó. Més endavant consten altres vestits d'En Ruvira: unes espatlleres de drap de fil, una gramalla de color gris-morat amb la seva caputxa i tres botons de corall, una túnica de roba verda amb tres dotzenes de botons d'argent, unes calces de drap vermell, dues dotzenes de botons d'argent. Al final de tot, com trobats més tard potser a l'obrador, hi ha una corretja de cuir vermell amb una bossa de cuir blanc, que podria ser una faltriquera per portar els diners, i un gavinet amb mànec d'ivori i virolla d'argent.

A més de tenir diners al banc, Ruvira guardava monedes a casa que consten a l'inici de l'inventari: 92 sous, 6 diners i un òbol en diners menuts barcelonesos de tern i 238 sous i mig en diners barcelonesos d'argent. Segueixen els millors objectes del capeller: una copa (ciphus) d'argent daurat a l'interior amb marca de la ciutat i pes de 10 unces; una taça d'argent també amb marca de Barcelona i pes de 4 unces, i una cinta de seda ornada d'argent amb tres dotzenes de platons o plaquetes decoratives d'argent, amb la seva agulla i la mosqueta d'argent, amb la corresponent bossa de seda. Segueixen robes i cordetes que semblen pertanyer al seu treball a l'obrador, i una caixeta de futs. 


\section{L'obrador del capeller}

L'obrador d'En Ruvira, molt ben provist, ens permet tenir una idea del seu treball, però no podem fer una generalització a base de les escasses dades i detalls que proporciona linventari. S'ha de partir de la base que disposava, dins de la variada mostra del gènere, d'un total de 284 capells. Si bé no es pot establir cap relació preu/capell per saber el capital esmerçat, és segur que és una bona quantitat i un capital elevat. Només és possible agrupar-los després de classificar-los segons la seva utilització, el color, el material o la forma.

El grup més nombrós és el dels capells de sol i n'hi ha 145. Suposem que la resta, solament anomenats capells, que són 139, tenen una utilitat diferent, més general. De fet trobem una diferenciació entreel grupo dels capells d'Alemanya: 60 són capells de sol fins i prims d'Alemanya i 16 estan definitis només com capells fins i prims d'Alemanya, característica que es deriva de la forma - d'ala més ampla els primers - o de la roba de procedència alemanya. També podria ser que fossin confecionats pel col.laborador de Ruvira, Enric d'Alemanya, segons la tècnica o la moda del seu país.

Més original, per ser únic, és un capell de sol castellà treballat amb seda i ornat del signe reial, ben guardat en una bossa de roba ratllada. Podria ser d'importació, com també dos capells de sol de Sicília, ornats amb una veta de seda verda i un altre de sol vermell amb la forma dels capells sicilians. Aquests devien ser els millors ornaments de la botiga enmig del gènere més normal i demanat pel públic.

Entre els barrets més sol.licitats, els de sol, destaquen els sis qualificats de grossets i blancs i els vint-i nou grossets que devien ser de color; per tant els altres eren més petits. Són més abundants els barrets de sol camellins (pot ser de pèl de camell ) prims o no, que es compten a dotzenes; altres de colors vermell, cendra, grisós no eren tan nombrosos. Predomina el color negre ( 38 capells 14 són de sol), seguit del lívido grisos (20), 16 són de sol, i n'hi ha 27 entre blancs i vermells, 24 ornats amb una veta de seda vermella i 27 amb veta de seda verda. Tots estaven ben guardats en caixes exceptat el grup del emperxats (13), és a dir exposats a l'interior i a l'exterior de l'obrador en perxes vermelles com a propaganda de la mercaderia. L'existència de 17 dotzenes de perxes vermelles a l'obrador fa suposar que Ruvira venia cada capell juntament amb la perxa corresponent potser per tenir-lo a casa a mà.

Com que no coneixem gaire la tècnica medieval dela confecció de capells, (24) només es pot afirmar que els més consistents havien de tenir una base, un cos de palla sobre el qual es posava la roba i es folrava. En el cas d'En Ruvira ens podem fixar en les robes emprades por ell, per què mai s'esmenta la palla ni com a material dels capells de sol ni com a base dels atres. En el seu obrador els barrets inventariats són de fil o sia de lii, o de fil 
fi ( 4 exemplars ) que són el més apreciats. També n'hi ha de camellí solament (18) o de camellí prim (27). No consta que n'hi hagi de feltre o de llana, com els al.ludits en les ordinacions dels capellers comentades a l'inici del treball, ni de seda; podria haver-n'hi perquè molts capells es comptabilizen sense cap descripció o només com de sol. S'esmenta la seda quan serveix d'ornament en forma de veta vermella o verda, o com a corda per subjectar els capells de sol; a més podia servir per folrar l'interior, ja que Ruvira tenia diverses peces senceres. Devia estar destinada a barrets de categoria aptes per afavorir el desig d'ostentació dels personatges dels estaments superiors i potser també de la familia reial.(25) A aquests clients estaven destinats els capells de Castella, de Sicilia o d'Alemanya i també els de fil que són molt apreciats, més que els de camellí, sembla.

A part dels barrets ja fets i guardats en tres taüts grans, consten les cintes de seda, cordes de llana, fil o seda, vetes i peces per ornar o cobrir part del capell. Observem que les de seda reben un tracte especial, encara que siguin trossos, i es guarden curosament tant en caixetes com embolicades en paper, detall que demostra el seu valor: dues peces de sendal de color safrà o sia groc, sis trossos de sendal vermell embolicats en un paper, una peça de sendal vermell embolicada en un paper, i dues dotzenes de cordes de seda per cordar els capells de sol. A tot això hi hem d'afegir un capell de sol de lli pentinat que es trobava entre la roba personal de Ruvira.

Per portar a terme la seva feina artesanal el capeller utilitzava diversos estris que consten en l'obrador, i altres que havia de tenir per la confecció de barrets, com agulles, didals, fils etc. pero no s'esmenten. També podria ser que ell ja no en fés i es dediqués exclusivament a la venda dels elaborats pels seus col.laboradors o dels importats. Tenia quatre formes de capells, que potser eren de diferentes mides, ja que tenia capells grossets $i$ altres que no ho eren. Altres eines directament relacionades amb l'ofici són dues tisores, unes grans de ferro i unes de petites també de ferro, esmentades a l'inici de l'inventari. Podien servir els següents materials: un puxó de ferro, un pern amb frasque (no sabem per què li podia servir), dues canes de canar per prendre mides de les robes $i$ vetes, un computador de fusta o àbac per portar els comptes.

Després de l'anàlisi dels béns del capeller inventariats dins de la seva casa-obrador, per la qual havia pagat 65 lliures - al cap d'un any la seva vídua l'adquirí per 80 essent "la més oferent"-, podem afirmar que el nivell socio-econòmic de la família era bastant alt dins del conjunt benestant dels mestres de l'abillament. En el pla personal el capeller disposava de bons vestits amb complements i adorns, o sia botons d'argent i de corall i folres de pells de conill, i una joia: una cinta de seda i argent amb tres dotzenes de platons d'argent amb agulla i mosqueta també d'argent. Pot ser un collaret? 
En l'àmbit del treball, constatem que tenia un gènere de qualitat i una mercaderia sortida, amb la confecció i venda de la qual podia donar feina a d'altres capellers, prestar a la menuda i encara fer viure tota la família. La seva activitat professional, només coneguda per la possesió de capells, complements i eines, no permet conéixer bé l'organització del treball, a part del nom d'alguns dels seus col.laboradors. Com tothom Ruvira tenia deutes, fet normal en una època en què no s'acotumava a pagar al comptat, i consten a la fi de l'inventari; són 9 lliures als fills del difunt Oliver, pellisser, perquè li havia comprat 11 dotzenes de perxes i 9 perxes més a raó de 15 sous la dotzena, i 10 lliures dipositades per la vídua d'un sababer. Com que la seva muller Benvenguda tenia béns propis, ell ho deixà tot a Déu i als pobres i per això els seus marmessors s'apressaren a vendre la casa que era la seva única propietat. El que ignorem és si els capells hi anaven inclosos i si el preu del gènere era una part de les 80 lliures pagades per la vídua, que potser sabia l'ofici i el podia continuar amb el seu fill. Només és una suposició. 


\section{NOTES}

(1) Aquest estudi forma part del projecte titular "Dades i fonts documentals per la història de Barcelona: municipi i societat (1249-1438)". Els treballs que ja hem publicat són: Els apotecaris de Barcelona en el món dels negocis pels volts de 1300, "Cuadernos de Historia Económica de Cataluña", XVIII (1978), pp. 97-109; Contribució a la història dels officis de Barcelona: els carnissers del segle XIII, "Quaderns d'Estudis Medievals", II (1981), pp. 310-318; Le travail à Barcelona vers 1300: les métiers, in "Travail et travailleurs en Europe au Moyen Age et au début des temps modernes", ed. Claire Dolan, Toronto, Pontifical Institute of Medieval Studies", 1991, pp. 79-102.

(2) Les quatre grans cròniques. Crònica de Jaime I, ed. F. Soldevila, Barcelona, 1971, paràgraf 266, p. 109.

(3) En tota la documentació treballada només consten aquests tres barrets un és "de pavone" (M. PALOMARES, La dona en el segle XIII segons els testaments, tesi de llicenciatura dirigida per C. Batlle, Universitat de Barcelona, febrer 1985, p. 88).

(4) Féu testament el dia 11 d'abril de 1277 deixant una fortuna ( C. BATLLE, La vida y las actividades de los mercaderes de Barcelona dedicados al comercio marítimo (siglo XIII), in "Le genti del mare Mediterraneo", I, Napoli, 1981, págs. 305309).

(5) M. RIU, La documentación del siglo XIII conservada en el archivo de la basílica de Santa María del Mar (Barcelona ), in "Jaime I y su época, 3, 4 y 5, Zaragoza, 1982, p. 593, doc. 3, 15-XII-1244.

(6) F. CARRERAS CANDI, La ciutat de Barcelona, "Geografia General de Catalunya", Barcelona, s.a., p. 367, nota 995.

(7) M. RIU, Aportación a la organización gremial de la industria textil catalana en el s. XIV, VII de Historia de la Corona de Aragón, II, Barcelona, 1962, p. 552.

(8) P. BONNASSIE, La organización del trabajo en Barcelona a fines del siglo XV, CSIC, Barcelona, 1975, p. 33.

(9) A. DURAN I SANPERE, Barcelona i la seva història, II: La societat $i$ l'organització del treball, Curial, Barcelona, 1973, p. 354.

(10) CARRERAS CANDI, op. cit., p. 376, 1 fig.

(11) En 1346 vivia l'anomenat Capeller, que ho devia ser també d'ofici, i deixà un objecte d'argent com a penyora per 2 sous deguts a l'escrivent Joan de Montrodat. Aquest darrer tenia dos capells de lii, segons l'inventari dels seus 
béns, com n'hi havia a l'obrador d'En Ruvira, protagonista del present estudi (C. BATLLE, Notes sobre l'aportació francesa a la demografia de la Seu d'Urgell (1150-1348), "Urgellia" 4 (1981), p. 284 ). Semblant a l'inventari de l'esmentat escrivent és el de l'obrador de Pere Roll de la mateixa data.

(12) BONASSIE, op. cit., p. 165.

(13) A. DE CAPMANY, Memorias históricas sobre la marina, comercio y artes de la antigua ciudad de Barcelona, reed., I, Barcelona, 1961, pp. 545-546.

(14) Capmany cita aquestes ordinacions que es troben a l'arxiu històric de la ciutat, sèrie IV, $n .916$ (1538-1549), fol. 128.

(15) Inventari transcrit a l'apèndix documental: Arxiu de la Catedral de Barcelona, Bernat de Vilarrúbia, man. 8 (1307-1312), fols. 56v-58.

(16) Document escrit dissabte 15 de març de 1309 (ACB, B. de Vilarrúbia, man. 9 de 1308-1309, fols. 200-201v).

(17) Document escrit pel notari Miquel d'Antiga el 17 de maig de 1308, que consta a l'inventari.

(18) Jaume d'Olivera estava casat amb Benvenguda, filla d'Arnau Llull; ferent testament el 1290 i 1291 respectivament.

(19) Els esposos venen una vinya per 68 sous el 9 de gener de 1255 (C. BATLLE, La Seu d'Urgell a la segona meitat del segle XIII segons els testaments, Urgellia, 3 (1980), p. 395 ). Vegeu la nota 11 del present treball.

(20) El document escrit per notari públic de Barcelona Ramon Cros consta a l'inventari juntament amb el de la procura, el rebut dels diners i la presa de possessió. La data de l'adquisició és incompleta per ser il.legible en part: 11 kalendes...1307, mentre que la del rebut és el 19 d'abril de 1308, com també la de la procura i de la presa de possessió. Per tant sembla que la primera data hauria de ser just abans del 25 de març del mateix any 1308.

(21) Aquesta descripció concorda amb la feta en el document del 15 de març de 1309, que és la venda de la casa del difunt capeller a la seva vídua $i$ al fillastre: limita a l'est amb l'hospici de Suau, al sud en la part inferior en la tinença de Pere Fluvia, i en la superior en la de Suau, a l'oest en la carrera del Mar al nord amb l'hospici de Ramon Ricard, en les tres parts amb parets comunes; la compradora pagarà un cens de 10 morabatins anuals als germans Oliveres per Santa Mariade febrer, comptant el morabatí a 9 sous. Els testimonis són Guillem de Puigrodó, Guillem de Colomer, Arnau de Roure preveres i Guillem dez Garrofar, apotecari ( $A C B$ B. de Villarúbia, man. 9, fols. 200-201v, i també 20-30v del 9-X1308, el 62-v del 22-X, 70v del 28-X.

(22) La descripció concorda amb la continguda en el document del dimarts 22 d'octubre que és la venda feta per Suau, per 63 lliures, als dos germans Oliveres de la finca que té el burg vora el "vicus" del Mar, definida com "spacia sive trocia terre" al costat de l'hospici; limita a l'est amb la "carraria publica" que va a l'església de Santa Maria i amb la carrera dita d'En Roudors, que és entre la primera carrera i el "vicum maris", a l'oest la tinença de Benvenguda, muller de capeller, $i$ al nord les cases de Guillem Baster (ibid., fols. 62-63).

(23) Vegeu inventaris de la mateixa època ja publicats: C. BATLLE, La familia i la casa d'un draper de Barcelona, Burget de Banyeres ( primera meitat del s. XIII), 
"Acta/Medievalia", 2 (1981), pp. 70-91; id., La casa i els béns de Bernat Durfort, ciutadà de Barcelona, a la fi del s. XIII, "Acta/Medievalia", 9 (1988); F. Sabaté, Els objectes de la vida quotidiana a les llars barcelonines al començament del segle XIV, "Anuario de Estudios Medievales", 20 (1990), pp. 53-108.

(24) Tracta de la seva evolució C. BERNIS, Indumentaria medieval española, CSIC, Madrid, 1956, pàgs. 17, 25, 27 i 43.

(25) La casa reial tenia els seus propis sastres, i segurament també algun capeller perqué el rei Jaume $\mathrm{I} i$ els seus fills posseïen molts barrets, per exemple l'infant Pere tenia un capell jubat de drap d'or amb garlanda de perles. Entre els cubricaps, galerum sive capellum de sole, aquestes darrers són els més nombrosos; un d'ells, del rei, és tan enjoiat i virolat, amb 312 perles grosses, altres pedres i llaços, que s'esmenta guardat entre les corones, garlandes i altres joies de preu. No consta mai cap capell femení de la reina o les infantes, ni de viatge ni de caça. Destaca el nombre de capells del monarca, que amb un gust molt personal preferia els capells de moda francesa $i$ el luxe oriental. ( J. E. MARTínEZ FERRANDO, Jaime II de Aragón, su vida familiar, Il: Documentos, CSIC, Barcelona, 1948, pp. 53, 72, 192, 210, 230 ). 



\author{
A C B Notari, Bernat de Vilarrubia, Mai 8 (1307-1312), folio 5bv-58 \\ 1309 , febrer, 11
}

Inventari dels béns de Pere Rovira, capeller, i del contingut de la seva botiga, fet per ordre seva, trobant-se malalt, a fi d'evitar l'ocultació o la dispersió de tot.(1)

Die martis tercio idus februarii anno domini millesimo $\mathrm{CCC}^{\circ}$ octavo.

(In) Dei nomine, Noverint universi, quod, cum ego Petrus de Ruvira, capellarius, civis Barchinone, sim detentus(2) agritudine et timeam ne bona mea dispendantur vel pereant aut etiam occultentur si forsan ex hac infirmitate(3) memori contigerit, idcirco ego dictus Petrus de Ruvira et ego etiam Benviguda, uxer eiusdem, presens inventarium sive memoriale de bonis mei dicti Petri facere curavimus ad cautelam.

Primus invenimus queddam hospicium cum pertinenciis suis in quo habitamus quodque tenetur per Guillelmum de Olivariis, civem Barchinone, et quod est in civitate Barchinone ${ }^{(4)}$ in carraria que dicitur de Mari. Item invenimus $\mathrm{XCll}$ solidos et $\mathrm{VI}$ denarios et obolum in denariis Barchinone argenti. Item invenimus I ciphum argenti intus deauratum marchatum Barchinone ponderantem $X$ uncias. Item unam taciam argenti marchatam Barchinone ponderantem quatuor uncias. Item unam scinctam de cirice munitam de argento cum tribus duodenis platonorum argenti cum sua fibula et moscheta de argento et cum suo marsupis de cirico. Item unam caxietam scilicet fustem. Item VI tracis de scindone in una papiro involuta. Item II pecias de scindone crocea. Item unam peciam de scindone virmilia in una papiro involuta. Item II duodenas cordarum de cirico factas ad muniendum capellos solis involutas in una papiro. Item alique trocio de scindone in una papiro. Item alique trocio de scindone in una papiro involuta. Item I tovalliolam operatam de cirico de opere sarracenico quam pro VI solidis minus duobus denariis tenemus impignoratam(5) Bernardo de Pulcro visu. Item IIII capdelles de fils lini. Item unam caxietam de fusto cum multis frustris sive(6) pecietis de scindone. Item invenimus instrumentum adquisicienis dicti hospicii, factum auctoritate Raimundi de Creso, / fol. 57 notarii publici Barchinone, XI kalendis... (anno) 
domini $\mathrm{M}^{\circ} \mathrm{CCC}$ 이으. Item instrumentum in quo dicta Suavis recognovit michi dicto Petro de Ruvira habueret et receperat omnes illas LXV libras monete predicte quas sibe (da) retenebat ratione dicte adquisitionis, quod instrumentum factum est auctoritate notarii supradicti XIII kalendas madii anno domini millesimo $\mathrm{CCC}^{\circ} \mathrm{VIII}^{\circ}$. Item instrumentum possessionis dicti hospicii, quod instrumentum factum est auctoritate notarii supradicti XIII kalendas madii anno supra proxime dicto. Item quoddam instrumentum procuratorium in quo dicto domina Suavis constituit Bernardo Sugnarii, maritum suum, procuratorum sius ad tradendum michi dicto Petro de Ruvira possessionem de dicto hospicis, idem instrumentum factum est auctoritate notarii supradicti XIII kalendas madii anno supra proxime dicte. Item IX instrumenta que Berengarius Aquilonis michi dicto Petro tradixit ex eo quare ego feci fideiussionem pro ipso ciudam traginerio qui vocatur En Sagalars, que instrumenta nos comendavimus Petro de Muntuinio, sabaterio civi Barchinone. Item quoddam instrumentum in quo Arnaldus Coch, baiulus Barchinone, laudat et approbat michi dicto Petro de Ruvira tabulas fusteas factas et fixas fronti predicti hospicii, quod instrumentum factum est auctoritate Michaelis de Antiga, notarii publici Barchinone, XVIo kalendas junii anno domini millesimo CCCo octavo. Item invenimus I lectum de fuste cum suo saccileto et matalafio et cum uno linteamine de line. Item I cuxinum operatum de cirico. Item I chopertorium de burdo. Item Ia vanovam albam. Item I caxiam scilicet fustem. Item invenimus aliud instrumentum in quo Gullelmus de Palacio confitetur se tenere in comanda a me dicto Petro de Ruvira $X$ libras, quod instrumentum factum est pro Bernardum de Solano, notarium publicum Barchinone XIII kalendas februarii anno domine $\mathrm{M}^{\circ} \mathrm{CCC}^{\circ} \mathrm{VIII}$ - .(7) Item invenimus unum banchum de fuste. Item un banchetum. Item I scutellarium sine scutellis. Item I⿳亠丷厂 patellam de arom fractam cum sua giradora de ferro. Item I lumenerium de ferro. item $l^{a}$ cohapertoriam de ferro. Item unas forfices de ferro parvas. Item I cultellum de ferro. Item un morterium de cupro cum sua manu de cupro. Item I lectum de postibus cum suo saccilecto et cum suo capciali de plumis. Item I flaciatam listatam. Item I banchum de fuste. Item unum ensem et I par cirotecarum. Item unum morterium de cupro cum sua manu de crupo, quod tenemus impignoratum( ${ }^{(8)}$ a Bonanato Estrany pro III solidis. Item quosdam petins. Item I chopertorium lividum ruptum. Item invenimus ${ }^{\mathbf{a}}$ caxiam in qua invenimus res sequentes, scilicet, unum supertunicalem de panno livido cum penna nigra cirogrillorum cum duabus duodenis botonorum argenti. Item I grmasiam de panno de rosem cum penna alba cirogrillorum et cum IIII magrinis argenti et cum suo capucio de eodem panno cum scindone/ fol. $57 \mathrm{v}$ virmilie. Item I per caligarum albarum. Item I linteamen...(grama)siam de lino...oricca. Item I linteamen vilem. Item I tovallionum de lino. Item I I $^{\text {aludam vacuam de }}$ corio albo. Item unam camisiam. Item I capdellos de filo stupe. Item unum computarorium(9) de fuste. Item I goern de ferro. Item I capellum de sole cum modico de lino pectinato. Item I cabas cum uno capello lini. Item Ia gramasiam 
lividam cum suo caputio livido cum tribus botonis de corallo. Item quasdam tovallias ruptas et I linteamen ruptum. Item $I^{\underline{a}}$ mensam abatam ad servicium(10) comedendi scilicet fustem. Item I capciale de plumis. Item I linteamen de stupa. Item I storium et Ia sistellam et I gavadal de fuste. Item Ia taciam de argenti quam pro pignore tenemus a Guillelmo de Palacis pro XXX solidis. Item I tunicam de panno viridi cum tribus duodenis botonorum argenti. Item quasdam caligas de panno virmilio. Item duas duodenas botonorum argenti. Item I bacinum de leutono. Item quasdam spatlerias de panno lini. Item invenimus in dicto hospicio I scitram de leutono et unam lanceam. Item unum postem ad servicium pannis. Item II duodenas capellorum nigrorum. Item decem duodenas capellorum et III capellos inter albos et virmilios. Item III capellos de colore cineris. (11) Item VIII ${ }^{\circ}$ capellos lividos empertxats. Item unam pasteriam scilicet fustem. Item I banchum. Item IIII formas capellorum et I sedacium ad opus(12) farine. Item unum postem fustis et I reetaule de fuste et unam caxietam. Item invenimus quod ego dictus Petrus Ruvira habeo in tabula Bernardi de Olivariis VIIIO libras monete Barchinone de terno. Item invenimus quasdam forifices magnas de ferro et unum punxorium de ferro. Item II canas de canar et unum pernum cum frascha et unas forfices magnas de ferro. Item invenimus in dicto hospicio $\mathrm{VI}$ duodenas de pertxes virmiliis cum Ia sarpayeria et cum I sarria. Item XI duodenas de pertxes virmiliis. Item invenimus unam thaut magnam in qua invenimus $V$ duodenas capellorum de sole subtilium sive(13) primorum de Alamannia. Item unam duodenam et IIII capellos subtiles sive (14) primos de Alamannia. Item II duodenas et II capellos camelins primis. Item unam duodenam capellorum camellinorum de sole et III capellos camellinos de sole. Item aliema duodenam capellorum de sole lividorum et IIII capellos lividos de sole. Item V capellos de sole grossets. Item VI capellos de sole(15) grossos et albos. Item invenimus in dicto hospicio aliam thaut magnam, in qua invenimus quinque duodenas et quinque cordas albas penitus de capellis de sole. Item III duodenas de cordis de lana. Item III duodenas de cordis virmiliis. Item IIII cordas de filo nigro. Item VII duodenas et IV cordas albas de parvo precio. Item I capellum camelinum de sole cum scindone viridi. Item alium capellum de sole castellanum operatum cum scindone ad signum regale et ipsi duo capelli sunt(16) involutis in uno manili listato. Item invenimus(17) III vetes de filo viridi. Item/fol. $58 \mathrm{~V}$ cordas de capeIlis de... Item XI cordas de scirico virmilio deauratas... Item $V$ capellos empertxats. Item I⿳亠丷厂 peciam vel quasi de veta viridi de filo. Item I⿳亠丷厂 peciam de veta scirice viridi. Item tres capellos de sole camelinos. Item III cordas capitatas de filo lini. Item II duodenas capellorum grossets de sole. Item II doudenas capeIlorum munitorum cum veta de cirico viridi. Item II capellos de sole de Cicilia munitos cum veta de cirico viridi. Item I capellum de sole virmilium ad fermam capellorum de Cicilia. Item invenimus in dicto hospicio aliam thaut in qua invenimus XIIII capellos nigros de sole. Item invenimus quod Petrus Terrassa, civis Barchinone, debet mihi dicto Petro Ruvire ex causa mutui $L$ solidos sine 
carta. Item debitum VIII solidorum et $\mid I I^{\circ}$ denarorium quod Bernardus Buscheti debet mihi Petro. Item debitum IIII solidorum quod Bernardus de Reguardosa debet mini dicto Petro quos sibi mutuavi ad opus tabulorum. Item invenimus quod Bartolomeus Capellarii debet mihi dicto Petro VI duodenas capellorum nigrorum de sole, quas VI duodenas debet mihi facere. Item invenimus quod tenet Berengarius Aquilonis XII capellos de sole nigros qui sunt inter me dictum Petrum et ipsum Berengarium. Item recognosco ego dictus Petrus de Ruvira quod debeo filiis Olivarii, pelliparii quondam, IX libras ex eo quare emi ab ipso $\mathrm{XI}$ duodenas et IX pertxes ad rationem XV solidorum pro duodena. Item recognosco ego dictus Petro quod teneo in comanda a domina Guillelma, uxore Raimundi de Graneya, sabaterii quondam, X libras. Item invenimus $\perp^{\mathrm{a}}$ corrigiam de corio virmilio cum marsupio de corio albo et cum uno gavineto cum manubrio de ebore et cum virola de argente. Item recognosco ego dictus Petrus quod de XCII solidis et $\mathrm{VI}$ denariis et obolo suprascriptis salvi XLVIII solidis Anrichi capellario et XX et IIII solidos et II denarios Barcelono, perpuntario.

Testes: Guillelmus Barceloni, perpuntarius, civis Barchinone, Anrichus, capellarius de Alamannia,(18) Bartholomeus de Columbario, presbiter, et Petrus de Muntuino, sabeterius, et Guillelmus de Portello, scriptor. 


\section{NOTES}

(1) Com que aquest manual notarial té en mal estat la part superior i la part lateral detra dels folis, hem indicat els forats amb punts suspensius en el text.

(2) Al marge, entre la primera i la segona ratlla, consta: cc.

(3) Tres mots interliniats.

(4) Tres mots interliniats.

(5) Mot interliniat escrit a sobre de pro pignore, que està barrat.

(6) Dos mots interliniats.

(7) Any interliniats.

(8) Mot interliniat escrit a sobre de pro pignore, que està barrat.

(9) Dos mots interliniats sobre un mot barrat.

(10) Tres mots interliniats.

(11) Tres mots interliniats a sobre senerosos.

(12) Dos mots interliniats.

(13) Dos mots interliniats.

(14) Dos mots interliniats.

(15) Dos mots interliniats.

(16) Cinc mots interliniats.

(17) Un mot interliniat.

(18) Un mot interliniat a sobre d'Alemanya, que està barrat. 